\title{
Showing Up for Immigrant Learners (and Each Other)
}

Andy Nash, World Education, Inc.

We are witnessing a mounting campaign in this country to blame immigrants and refugees for our economic insecurity, rampant violent crime, and a diminished social safety net. Under this banner, our government is using immigration policy to turn away asylum seekers and refugees, separate children from parents, and threaten the Temporary Protected Status (TPS) of communities that have lived in the United States for a generation and consider this their home.

Turning us against our immigrant neighbors is not a new trend. It is an example of a timetested divide-and-conquer strategy that is quite effective at redirecting legitimate grievances (low wages, unaffordable health care, etc.) away from the powerful who benefit and toward an easily identifiable (by accent or skin color) "other." And the result of this targeting, as Larotta notes in her piece, "Immigrants Learning English in a Time of Anti-Immigrant Sentiment," is that many immigrant groups are reporting increased incidents of intimidation and harassment, and many English language learners who come to our programs describe living in fear.

Educators everywhere are trying to figure out how to address this new reality - how to make sure that all students feel safe and able to learn, how to encourage critical thinking about daily events, and how to break down the manufactured fear of black and brown immigrants that keeps us from coming together to build alliances. None of us wants to be the frog in the proverbial pot that waits as the temperature slowly rises until it's too late to do anything.

There are things we can do. Some involve challenging the conditions that fuel immigration - the poverty, repression, and danger that drives people from their homes - and others focus on creating the conditions here that nurture connection to one another and discovery of the commonalities and differences in our experiences.

In adult education classes, we can demonstrate our commitment to creating safe learning spaces for all, and to thinking critically with our students about the causes and effects of this ongoing campaign. Below, I share and build upon some of the promising practices I've seen implemented in adult $\mathrm{ABE}$ and ESOL programs.

\section{For Classroom Teachers}

In the classroom, we need to think first about immediate harm reduction, and then we can plan for a curriculum that includes serious practice of the critical analysis skills highlighted in our rigorous learning standards.

Build safety through community. Immigrants 
attend all kinds of adult education classes, not just English language classes. Many teachers include activities that engage students in sharing their experiences and finding their commonalities - not just personal characteristics such as how many sisters they have but talking about how an issue touches their lives on a daily basis getting their kids to eat, finding a living-wage job, dealing with weather (climate change) disasters. Sharing experiences puts the voices of students at the center, developing their agency in naming, discussing, and analyzing issues and ideas. And building relationships with real people is a powerful inoculation against hate.

There are practical ways to do this kind of community-building that also attend to language learning, with all the related grammar, pronunciation, and vocabulary building. You can find wonderful examples in the archived webinars of the Immigrant Learning Center ${ }^{1}$ and the New England Literacy Resource Center. See also The Change Agent ${ }^{3}$ and Welcoming America's toolkit for adult educators ${ }^{4}$.

Teach analysis of the big picture. While it's important to note current events as they are happening, educators don't have the capacity to respond to daily upheavals - nor is it helpful to focus on what drains and disheartens. We can instead help students step back and study an issue more deeply by organizing instruction into thematic units that encourage students to name their concerns, ask and investigate their own questions, and develop the language skills to express informed opinions. This would include opportunities to consider "why" questions - why this? why now? - that honor the ability of students at any level to draw on their learning and their life experiences to analyze what they see.

Here's a quick mention of some topics, skill areas, and questions you might include in a unit:
- Media literacy: What is reliable news? What is fake news? Why is there fake news? How do we distinguish objectively descriptive from subjectively persuasive language and evaluate the bias of a text/source? (Resources: Mind Over Media ${ }^{5}$, The News Literacy Project ${ }^{6}$, "Don't Get Duped"7)

- History: People created our institutions and systems (our schools, our economic system, etc.) and people can change them. History offers up many examples of how communities and social movements have been able to advance justice in the past and can do so again. History also helps us understand the origins of current policies, attitudes, and behaviors. But since that history is usually written by the "victor," we need to check multiple sources and remind students to consider: Whose perspective is reflected here? Whose is missing? (Resources: Teaching for Change $^{8}$, Zinn Education Project ${ }^{9}$ )

- Critical analysis: How is a problem defined by different stakeholders? What questions do we need to ask in order to fully understand an issue (e.g., Who benefits? Who is hurt? Who is making money?)? (Resources: Right Question Institute ${ }^{10}$ )

In developing a unit on Immigration (for ESOL or $\mathrm{ABE}$ ), in addition to all the level-specific lessons we might do about the fact that people throughout history have been on the move (using maps, graphs, images, and other visuals to support learning), we might consider the categories above to help frame class discussions and activities:

Building community: What do you know about your own family origins (Native American, immigrant, refugee, or enslaved)? What is a question you have about your family origin?

History: Why do people come here? What is 
happening in their countries? (Extra credit: What role has the U.S. played in their countries? In your own?)

Critical analysis: How do asylum-seekers describe their reasons for coming to the border? What does the administration suggest are the reasons? What does the evidence suggest?

Media literacy: How is terminology used (asylumseekers vs. invaders) to influence a reader about immigration? What other language devices are used to persuade readers?

Find each other. It can feel disorienting to work in a field that has become almost solely focused on workforce preparation in a time when basic human dignity and connection are on the line. To keep moving forward, concerned educators need to support one another as we continue our own self-education, speak up where we can, share resources, and reflect on the assumptions underlying our work. What are the implications, for example, of defining the purpose of adult education to be almost exclusively well-being through individual employment? What will we do when we're expected to turn away students based on a newly criminalized immigration status?

We can help each other grapple with these perplexing questions and find the courage to follow the internal moral compass that points us toward protecting the rights of our immigrant (and otherwise targeted) friends. (Resources: LINCS discussion boards, Facebook groups, local immigrant and racial justice groups).

\section{For Program Leaders}

Program leaders have a crucial role to play in communicating support for all students.

Explicitly demonstrate solidarity with vulnerable students. Adults who are at risk of being targeted (immigrant, LGBTQ) anywhere in the community need to know that the program is a safe space. Leaders in many programs are making it clear (through banners or public statements) that hate is not welcome in their programs and that all residents are invited there to study and learn. Such declarations set the tone of the program and model how to speak up in solidarity with our neighbors.

Organize program-wide projects. Celebrations of any sort that bring students together informally to learn, mingle or break bread do a lot to build community and dispel fears. And as Larotta suggests, creating space for program-wide learning (bringing in speakers to talk about community resources, events, or issues; organizing student-researched voter education campaigns; hosting "Know your Rights" workshops and legal clinics; or hosting an awareness event about the upcoming Census 2020 - the importance and the risks) opens up opportunities for students to interact about a topic of common interest. Very important is introducing students to community organizations, both service organizations that can help them build their support networks and activist/advocacy organizations they can join to organize collectively for themselves.

\section{For Adult Education Advocates}

Advocate for inclusive services. Funding sources each come with their own rules and regulations. At a time when federal and some state funders are looking for ways to limit the access of our immigrant students to all kinds of services, it is incumbent upon us to push back on those restrictions and to seek out other funding that allows us to continue full services to all residents of our communities. The recent proposal to broaden the way the government determines who may be a "public charge" (and therefore ineligible for public services) is just one example of efforts 
to vilify and exclude current and future language learners from our programs.

Build alliances. Adult education advocates have historically been guided by the maxim that we need to focus our advocacy message exclusively on adult education funding. And while that targeted message has yielded certain results, the practice of staying in our advocacy silos competing for funds has not advanced a united cross-issue movement that reflects the intersectionality of our students' (and our) struggles. Adults are not just immigrants or students or parents or patients or workers, and now more than ever we need to build alliances with all the movements working to help people get free. The Massachusetts Coalition for Adult Education, for example, has allied with labor organizations on the Fight for $\$ 15$ and with

\section{For More Information}

${ }^{1}$ Immigrant Learning Center (www.ilctr.org/promotingimmigrants/ilc-workshops/)

${ }^{2}$ How to be an Effective Ally to Adult Students, The New England Literacy Resource Center (https://bit.ly/2AyjzaU)

${ }^{3}$ The Change Agent magazine for teaching resources and compelling student writings (changeagent.nelrc.org).

${ }^{4}$ Welcoming America's Instructors' Toolkit for Building Bridges Across Communities (https:// www.welcomingamerica.org/content/ instructors\%E2\%80\%99-toolkit-building-bridgesacross-communities)

${ }^{5}$ Media Education Lab's Mind Over Media webpage (https://propaganda.mediaeducationlab.com/) offers teaching resources to support students to think critically about propaganda and the messages all around them. immigrant rights organizations on many issues; and conversely, those organizations have added adult education funding to their own priority lists.

\section{Conclusion}

I would like to be part of an educational community that helps one another find the courage to creatively resist unjust immigration and economic policies where we can. I don't want to have to look back one day and wonder what I was doing as xenophobia was being used to destroy lives and entrench the powerful. I am so grateful to the adult education coalitions, justice organizations, and individual educators who are refusing to be too busy to respond to these dangers. I hope we can all find ways to show up for our immigrant learners and each other.
6 The News Literacy Project, (http://www. thenewsliteracyproject.org) is a national education nonprofit offering nonpartisan, independent programs that teach students how to be critical media consumers in the digital age.

7 Alicia Shepard, Don't Get Duped, (http://www. nationofchange.org/2016/12/12/savvy-newsconsumers-guide-not-get-duped)

${ }^{8}$ Teaching for Change (teachingforchange.org)

9 Zinn Education Project (Zinnproject.org)

${ }^{10}$ Right Question Institute (rightquestion.org) 


\title{
Review of The Mayor of Moultrie Avenue
}

\author{
Christine Miller, Georgia State University
}

When Carl Walworth began volunteering as a literacy tutor in Mattoon, Illinois, he did not realize that he was making a 24-year commitment and a lifelong friend in Eldo, his student. The Mayor of Moultrie Avenue: The Literacy Journey of an Unlikely Pair serves as both a memoir and a description of an adult literacy tutoring relationship. While working at the local newspaper as a reporter, Carl began volunteering with a local literacy program as a tutor. Part of what motivated him was curiosity about adults who struggle with reading.

Throughout his narrative, Carl actively contrasts and compares himself to Eldo as a means for better understanding the complexities of adult literacy in the United States. Eldo is a generation older than Carl, but they both come from small towns in Illinois. While they have led parallel lives in some ways, socioeconomic class divides them in other ways. The child of educators, Carl initially cannot understand how an individual can go to school and not achieve literacy proficiency. Further, Carl's parents raised him with the middle class assumption that college followed high school graduation. Carl's relationship with Eldo helps him to see how socioeconomic class narrows or widens opportunities and expectations.

As a child of the 1950s in a working class neighborhood of Mattoon, Illinois, Eldo struggled with reading even though his reading delays were not remarkable to his family and friends. He began working to help his large family around the age of 12 , and it was felt that it was possible for him to grow up and make a comfortable living without advanced reading skills or a high school diploma. As Eldo became an adult, the changing economy of an 
increasingly automated and globalized United States constrained his ability to support his family, and it became progressively more difficult for him to do so. These changes meant that Eldo had to work harder for less money and fewer benefits. When he and Carl meet, Eldo has survived a major stroke, which left him permanently disabled along with other chronic health issues such as diabetes and an enlarged heart. By the end of the memoir, a fiftyish Carl himself experiences the effects of the changing economy in his own career at the newspaper, which is cut short by the Great Recession.

Carl Walworth gives an authentic account of the challenges facing adult tutors and their reading students. Adult learners must juggle jobs, family commitments, illnesses, etc., while working on increasing their reading skills. Carl layers the story of his tutoring relationship with Eldo by giving readers the historical background of Mattoon, sharing Eldo's own insights about how he survived with limited reading skills on the job, explaining how the literacy tutoring program operated, and offering practical tips for readers who may be interested in tutoring adults.

A strength of this book is that Carl personalizes the millions of adults who struggle with reading in the United States. Eldo is multi-dimensional; he is intelligent, resilient, and actively involved in his community despite struggling with limited reading skills. Tutoring milestones are described and one special one is their shared reading pleasure over Mark Twain's classic, The Adventures of Huckleberry Finn.

The book is not structured in a strictly linear fashion, which enlivens the story. The writing is strongest when Carl dons his reporter's cap and gives his writing a clearer, more objective tone. While Carl gives general information about assessing progress and reading activities with his students, more details about this aspect of tutoring would have been interesting to readers who are involved in adult basic education. In addition, Carl provides many details that are not related to literacy, such as information about the community and his own life. The details are not tightly connected to the tutorial relationship and therefore at times the descriptions are a bit tedious.

This book is best suited for individuals who are unfamiliar with adults who have difficulty reading and who want to learn more about the experience a tutor can have with a learner. The book concludes with ideas about places where volunteers can help others with reading including community programs, schools, libraries, community colleges, and faith based organizations. There is a section at the end of the book which provides a list of adult literacy resources. I recommend this book for those who are not familiar with adult literacy learners and tutors. Through his tutorial relationship with Eldo, Carl Walworth connects the dots between literacy, education, healthcare and poverty in blue collar, Middle America. 


\title{
Research Digest
}

\section{Fostering Transformative Learning in Educational Settings}

\author{
Lisa M. Baumgartner, Texas A\&M University
}

The word "transformation" evokes images of profound change such as caterpillars turning into butterflies or humans shape-shifting into werewolves. Transformative learning refers to a perspective transformation or change in worldview. Teachers in literacy education and adult basic education as well as GED instructors can learn how to foster transformative learning. These techniques can help learners engage in critical thought and discussion with others and may gain a broader, more inclusive view of themselves and their world.

There are scholars that discuss transformative learning using a variety of frameworks such as Freire's social-emancipatory framework or Daloz's developmental framework. However, it is Mezirow's framework that has been used in many empirical studies. Specifically, Mezirow (2000) describes a 10-phase process that results in a change in world view or perspective transformation. This begins with a "disorienting dilemma" which is an event or series of events that jar a person from their previous ways of thinking (Mezirow, 2000, p. 22). Most often, it is seen as a single event, such as a death or divorce, that causes a person to critically reflect on his or her previous assumptions about the world although a series of events can also lead to a perspective transformation (Mezirow, 2000). Questioning the issue itself, or what Mezirow calls premise reflection, most often results in perspective transformation. Questions such as: "Why is getting my GED important?" Why am I in this job?" are the types of questions that trigger perspective transformation (Cranton, 2016). In addition to critical reflection, individuals engage in reflective discourse or dialogue. Mezirow (2003) defines discourse as "dialogue involving the assessment of beliefs, feelings, and values" (p. 59). Questions from others help individuals think through their new beliefs. Through critical reflection and talking with others, people change their perspectives on the world. In Mezirow's (2000) view, this change in how one sees the world is permanent.

Cory's experiences may exemplify a perspective transformation. Cory dropped out of school in $10^{\text {th }}$ grade. At age 25, he married, and he and his wife had a son. Cory knew he needed more education to obtain a better job to support his family. However, he was extremely anxious about returning to school to obtain his GED due to his previous schooling experiences which led him to believe he was not smart enough to complete a GED. He asked himself, "Why is this anxiety overwhelming? Aren't lots of people anxious?" (Cranton, 2016). He attended his first GED class and realized, after talking with other classmates, that many people were nervous about returning to 
a formal classroom setting. Thorough interactions with others and the support of his instructors, Cory gained increased confidence in his academic abilities and began to see himself as a smart, capable student.

\section{Elements that Foster Transformative Learning}

Cory's transformation from an anxious to a confident learner was fostered through critical self-reflection, dialogue with others, and a supportive educational environment. Mezirow believed that fostering transformative learning was "a central activity" of adult education (Taylor, 2000, p. 5). Mezirow stated that dialogue fostered transformative learning. He noted conditions that helped facilitate transformative dialogue including: creating a safe environment where trust can be established, having accurate information, using student-centered approaches in the classroom and examining issues through "problem solving activities and critical reflection" (Taylor, 2000, p. 5).

Taylor $(2000,2009)$ reviewed empirical studies that discussed fostering transformative learning in an educational setting. The studies confirmed Mezirow's ideal conditions for engaging in dialogue. A more recent study concerning prison educators' views of facilitating transformative learning also noted that having a respectful relationship with students and serving in a counseling role where dialogue could occur, and students could "risk what they do not know" encouraged transformative learning. Using humor in the classroom helped cultivate these trusting relationships (Keen \& Woods, 2016).

In addition to confirming Mezirow's ideal conditions for encouraging transformative learning, Taylor (2009) uncovered six interdependent elements that nurture transformative learning in educational settings. First, individual experience, including a learners' prior experiences as well as what he/she is experiencing in the learning situation is necessary to stimulate transformative learning (Taylor, 2009; Taylor \& Laros, 2014). Taylor found that nurses with more experience may be able to take in new points of view more easily that those with less experience (Craigg, Plotnikoff, Hugo, \& Casey, 2001 as cited in Taylor, 2009). Having value-laden course content is important. Discussions about topics such as spirituality, abortion, and death can create the conditions for transformative learning to occur (Taylor, 2000). For example, medical students' attendance at a session on palliative care that allowed students to interact with families of dying patients prompted critical reflection (MacLeod, Parkin, Pullon \& Robertson, 2003, as cited in Taylor, 2009). This activity provided a catalyst for change as well as the opportunity to talk about the experience with others and gain self-awareness - all of which is integral to the transformative learning process.

Second, critical reflection promotes transformative learning. Critically reflecting on a situation means "questioning the integrity of deeply held assumptions and beliefs based on prior experience" (Taylor, 2009, p. 30). Kreber's (2004) study that looked at the content, process, and premise reflections of teachers confirmed that asking premise reflection questions of teachers increased meaning-making (as cited in Taylor, 2009). Instructional aids that promoted critical reflection include journal writing as this method encourages individuals to record and reflect on experiences (Taylor, 2009).

A third component that aids transformative learning is dialogue that emphasizes "relational and trustful communication" (Taylor, 2009, p. 31). Analytic discussions are important, but teachers 
also need to attend to "learners' attitudes, feelings, personalities, and preferences over time, and as signs of change and instability begin to emerge, educators can respond accordingly" (p. 31). Taylor, Duveskog, and Friis-Hansen (2012) investigated the transformative learning of participants who attended Field Farmer schools in Kenya. These schools were "community-led [non-formal education programs] ... where farmers met regularly to study farming" (p. 725). Interviews with participants revealed that individuals' experiences and group dialogue fostered transformative learning.

Understanding transformative learning as a holistic process is also an important element. This perspective accounts for feelings and relational ways of knowing (Taylor, 2009). Using music, drama, dance, and storytelling are ways to engage the whole person (Taylor, 2009). Hoggan and Cranton (2015) completed a case study that looked "the role of fiction in promoting transformative learning in content-based courses" (p. 8). The students read a "short story that incorporated metaphor and symbolism to explore the concept of the personal construction of knowledge" (p. 12). After reading a story, participants reported that the story evoked emotions, helped them open their eyes to new perspectives, and engage in critical reflections on past experiences (Hoggan \& Cranton, 2015). Hoggan and Cranton (2015) concluded that fiction can "provide an intellectual and emotional catalyst by which readers can fully engage in processes that are at once empathic, as well as reflective and imaginative" (p. 20). Fiction prompted emotion and "allowed for an emotional distancing that made it easier for readers to question deeply engrained ways of thinking and being" (p. 21). Further, after reading fiction participants new perspectives were more holistic.

Next, teachers need to understand the part that personal and sociocultural factors play in the transformative learning process. This includes what is happening in the learning event, the prior experience of the learners, and how that might influence their learning. Transformative learning and perspective transformation take time because "the very conditions that foster transformative learning-a democratic process, inclusiveness of agendas, striving for consensus, critical reflection, dialogue - create a high demand for time" (Taylor, 2009, p. 33).

Last authentic relationships promote transformative learning. Carter (2002) examined women's midcareer work-related relationships and found four types of relationships: utilitarian (acquire skills and knowledge), love relationships (friendship or relationships that enhance self-image), memory relationships (relationships with deceased individuals), and imaginative relationships (selfrelationships or meditation). It is the last threelove, memory, and imaginative relationships that fostered transformative learning (as cited inTaylor, 2009). Authenticity as it applies to teaching includes strong awareness of oneself as the teacher, how learner interests and needs may differ from teacher needs and interests, being genuine and open with others, looking at how context shapes teaching practice and critical reflecting and self-reflecting about practice (Cranton \& Carusetta, 2004, as cited in Taylor, 2009).

\section{Practical Advice for Fostering Transformative Learning in Educational Settings}

How can an instructor translate these elements into the classroom? Cranton (2016) provides advice for fostering critical self-reflection which can encourage transformative learning. As noted by Mezirow (2000), content, process, and premise questions can serve as a catalyst for transformative 
learning. Content questions "serve to raise learner awareness of assumptions and beliefs" (Cranton, 2016, p. 108). An example of a content question is: "What do you know or believe about yourself?" (p. 108). Process questions "help learners find the source of an assumption or belief; sometimes it is useful to ask people if they can recall a time when they did not hold a particular belief and then work forward from that time" (p. 109). Questions like: "Can you recall how you came to hate reading?" is an example of this type of question. As previously mentioned, premise reflection questions focus on our core beliefs. A question such as "Why is it relevant what your extended family thinks about your decision to pursue your GED?" exemplifies this type of question.

Individuals can participate in consciousnessraising activities that may help them see things differently. Role-playing is a method used to do this. Cranton (2016) says that typically the purpose of the role-playing activity is described and people are given different roles and they improvise. She recommends that role-plays be "co-constructed with the educator" (p. 111) and that debriefing occur so people can discuss their experiences. Simulations can be helpful also. For example, equipping students with devices that simulate the sight lost due to macular degeneration or glaucoma may help students understand the physical challenges faced by older adult learners. Likewise, giving learners a minute to read a paragraph where the letters are reversed, transposed or inverted may provide students a window into some of the challenges experienced by individuals with dyslexia.

Journaling activities can foster critical selfreflection. Cranton (2016) provides specific suggestions for journal writing such as dividing the page into two sections and writing thoughts on one side and feelings on the other, exploring themes related to the course, and making sure learners know they don't have to worry about spelling and grammar. Educators can read these journals and provide additional questions or comments that can foster transformative learning and a dialogue between the educator and learner can occur.

The critical incident technique, originally a method used in qualitative research and adapted for education, is another technique. Learners are asked to think about a positive or negative event that happened in the last year. They describe the event, indicate why it was particularly positive or negative, and the insights they gained. Cranton suggests that educators consider modeling the critical incident and having students question it, having learners share critical incidents in pairs, coaching learners on what questions to ask, and "including some action planning in the discussion by asking, 'What would you have done differently?"” (p. 117).

Cranton (2016) also advocates for arts-based activities that encourage creativity and imagination. She recommends such activities as having students create a collage that "represents the critical questioning of a social norm or an assumption in the field of study" (p. 119), writing fiction or poetry that "critiques a point of view. . instead of the traditional essay or paper" (p. 119), or having students write a play "to represent conflicting or alternative points of view on an issue" (p. 119).

In addition to activities that can foster transformative learning, there are ways that educators can support transformative learning. As previously mentioned, authenticity can promote transformative learning. Authenticity is shown through showing interest in students' learning, sharing stories from their own lives, 
learning from students, asking if students are comfortable or need help, and being accessible. Groups can support and foster transformative learning also. Supportive groups have some common characteristics: they are committed to the group goals, loyal to the group, have good communication amongst each other, accept each others' opinions, and have the ability to endure frustration" (Cranton, 2016, p. 126). Third, learner-networks can promote transformative learning. Learner networks are relationships among learners in an informal or formal setting or a relationship outside that group. Cranton says that peer-teaching, referring learners to each other for answers to issues, encouraging study groups, forming project groups and using small group activities can foster learner groups.

Cranton (2016) reminds educators of the ethics of fostering transformative learning. She says it is important for educators to ask themselves what right they have to encourage people to question what they believe. When does this type of activity become an imposition? She reminds educators to be mindful of the power differential between learners and educators and to respect learners' values while still providing activities that question them.

In summary, researchers found six elements that promote transformative learning. These elements are: individual experience, critical reflection, dialogue, seeing transformative learning as a holistic experience, the importance of sociocultural and personal factors, and authenticity. Some tools that teachers can use to foster transformative learning in an educational setting include: asking questions that cause learners to reflect on what they are doing and why they are doing it, role-playing, simulations, arts-based activities, using the critical incident technique, and encouraging learner support groups and group-based activities. These elements and activities will provide learners, such as Cory, opportunities to expand their worldviews. 


\section{References}

Cranton, P. (2016). Understanding and promoting transformative learning: A guide to theory and practice. Sterling, VA: Stylus.

Hoggan, C., \& Cranton, P. (2015). Promoting transformative learning through reading fiction. Journal of Transformative Education, 13(1), 6-25.

Keen, C. H., \& Woods, R. (2016). Creating activating events for transformative learning in a prison classroom. Journal of Transformative Education, 14(1), 15-33.

Mezirow, J.\& Associates (2000). Learning as transformation: Critical perspectives on a theory-inprogress. San Francisco, CA: Jossey-Bass.

Mezirow, J. (2003). Transformative learning as discourse. Journal of Transformative Education, 1(1), 58-63.
Taylor, E. W. (2000). Fostering Mezirow's transformative learning theory in the adult education classroom: A critical review. CJSAE/RCEEA, 14(2), 1-28

Taylor, E. W. (2009). Fostering transformative learning. In J. Mezirow \& E. W. Taylor (Eds.), Transformative learning in practice: Insights from community, workplace, and higher education (pp. 3-17). San Francisco, CA: Jossey-Bass.

Taylor, E. W., Duveskog, D., \& Friis-Hansen, E. (2012). Fostering transformative learning in non-formal settings: Farmer-Field schools in East Africa. International Journal of Lifelong Education, 31(6), 725-742.

Taylor, E. W., \& Laros, A. (2014). Researching the practice of fostering transformative learning: Lessons learned from the study of andragogy. Journal of Transformative Education, 12(2), 134-147. 